\title{
PUBLIC PARTICIPATION IN THE PROCESS OF IMPROVING QUALITY OF THE URBAN FRAME
}

\author{
A. GALIANO, V. ECHARRI, \& A. ESPINOSA \\ Department of Building Technology, University of Alicante, Spain
}

\begin{abstract}
The different tools for analysing the quality of public space are coincident when showing that a healthy urban space is conditioned by a proper urban structure. It is needed a balance between urban uses and a proper connectivity among the different parts of the city. At the same time, the users of the public space must have an adequate perception of the urban space it occupies; a good sense of identification of the user over the urban frame allows a proper use of the public space.

The development of urban analysis in the city of Orihuela, using tools as RGBG Strategic Model, showed junk urban spaces around the Mount St. Michael. The application of the RGBG allowed the identification of social conflictive areas that had a limited connectivity with the rest of the city and inhabitants with a low feeling of identification with the closest urban area.

The municipality of Orihuela used the knowledge acquired with these analysis tools for developing interventions over the public urban space focused on the detected social conflictive areas. With them, the municipality tried to improve the perception that inhabitants had over their closest urban environment. Public employment initiatives were developed with the participation of local inhabitants in order to integrate them in the process of recovering the conflictive urban areas.

This paper describes the process developed and shows that once these interventions were finished, it is possible to validate the data obtained with the urban simulation tools. It is confirmed that the perception of the quality of public space is improved when the inhabitants are involved in the process of its recovery and when urban factors as connectivity are improved.

Keywords: $R G B G$, public space, $R G B G$, urban connectivity, urban identity.
\end{abstract}

\section{INTRODUCTION}

The urban growth of the Mediterranean cities has been conditioned in most of cases by its economical development. The process of extending the city started by leaving the historical centre and developing new neighbourhoods in the city outskirts. When the prize of the plot became extremely high or when new developments were not possible, investors turned their sight to the most of the times abandoned historical city centre starting a wild process of substituting buildings. Then, a definite modification of the city frame and its image occurred till protecting regulations were developed.

Nevertheless, there are some city areas that have been out of this process and they reached an extremely high level of unrest and abandon. They became city junk spaces where efforts of the municipality have been concentrated in order to recover them. These junk spaces usually are placed at the city borders, far from the city core, but in some cases, they are in the very centre of the cities in places where the urban frame got incomplete.

In most of the cases, in their origin, regular citizens occupied these parts of the city but once the area could not develop at the same time than the test of the city, it was abandoned and it was colonised by new inhabitants with a lower level of integration in the city life. These

This paper is part of the Proceedings of the $11^{\text {th }}$ International Conference on Urban

Regeneration and Sustainability (Sustainable City 2016)

www.witconferences.com 
areas are characterised by a high number of illegally occupied houses and by the deterioration of the public space.

\section{THE PERCEPTION OF THE URBAN FRAME}

The perception of the built environment is one of the great challenges while acting in the cities. The way that people interact with their close environment is conditioned by the interpretation that they make from it. Kevin Lynch in "Image of the City" [1] defends that a person in an urban situation uses his own mental map for guidance identifying the urban frame milestones and circuits. The feeling of identification reinforces the feeling of belonging to a certain place and that includes the elements that define it.

Arnold Reijndorp in the book "In search of the new public domain" [2] states that there is a relation between the physical environment and human perception of spaces. The analysis of the cultural structure of the city shows that the intensity, diversity, overlapping and interaction between uses and users condition the value of the public domain.

The aforementioned theories have been further developed in the urban analysis methodology known as 1st, 2nd and 3rd Order or Three-Step Analysis [3] created by Peter de Bois, which places special emphasis on the pedestrian trajectory to one of its most significant points within an urban fabric. The analysis done in Amsterdam is shown as an example at Fig. 1. This method is directly related to the FPC Frame, Pattern and Circuit Method [4] that it is based on the mapping and optimisation of the link between the physical structure of a public space (Frame) the dispersion of the programme, and the socioeconomic landmarks (Pattern) and the current network of use and circuits implemented in the system by the inhabitants (Circuit).

Finally, the Danish urban designer Jan Gehl in the book "Life between buildings: Using public space" [6] claims that in order to achieve an adequate quality of urban space there should be a balance of activities so that a sustained use of the space is made throughout the day.

\section{JUNK SPACES AND THE URBAN FRAME}

The existence of junk spaces in the urban frame is always related to the natural development and the human perception and valuation of the cities. Traditionally, objective and subjective factors have conditioned the value that inhabitants give to the different urban areas.

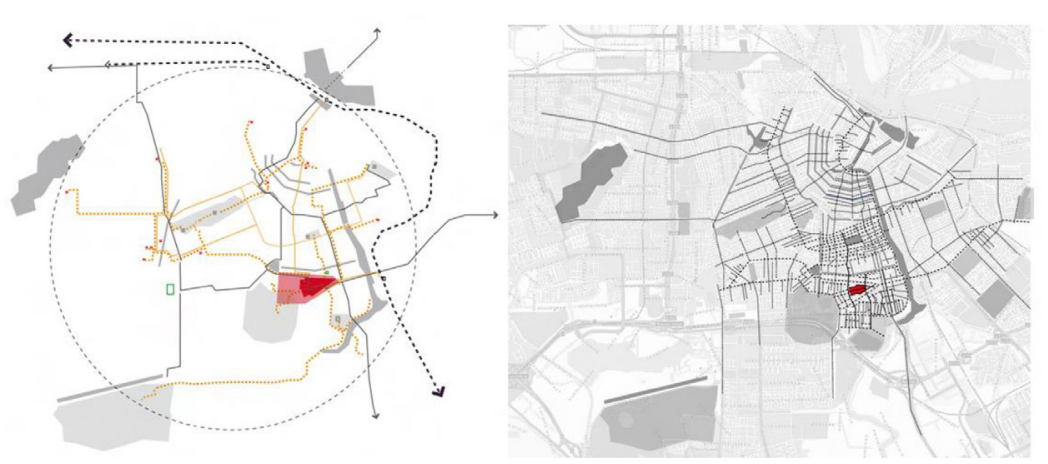

Figure 1: 1st, 2nd and 3rd Order analysis. Cognitive and available frame, Amsterdam [5]. 
Geometrical factors as street wideness, illumination, orientation and ventilation can be one of the factors that condition people election of the place to live. Traditionally, Mediterranean Spanish cities had this kind of problems, as the urban frame is a direct heritage from the Arab times as it can be seen at Fig. 2. Narrow streets with complicated geometry and totally insufficient open spaces define the city centres and use to have connectivity and mobility problems.

The compatibility of uses is another factor to be considered at the moment of rejecting living in a certain area. The establishment of annoying uses and the adoption of wrong political decisions can make some parts of the cities become unpleasant for people in a short period of time. The allowance to set noisy activities in the cities or the development of a wrong use of public space can make some parts of the cities hard to live. This case is reinforced in the Mediterranean cities were climate allows living outside the buildings.

But in other cases, conflictive spaces are related with non-solved limits of the urban frame. The existence of orographic elements in the urban fabric, such as mountains and rivers, may make the city define urban junk spaces in these areas. In the Mediterranean cities, rivers have not been considered as a potential city milestone, and most of the time, its use has been related as part of the sewage system making housing to be constructed giving their back façades to them.

The proximity of mountains to the city centre use to be a place where urban junk spaces can be found. Traditionally, the mountain's slope is the place where lower level housing is allocated in the Mediterranean cities. Mobility difficulties and the distance to the main city uses use to be reasons why quality of public space decreases in these areas.

Nevertheless, some authors as Rem Koolhas [7] define those urban junk spaces as spaces of opportunity. The integration of these spaces in the city life can be done if a proper intervention is developed and if users are helped to understand the identifying invariants that these spaces have.

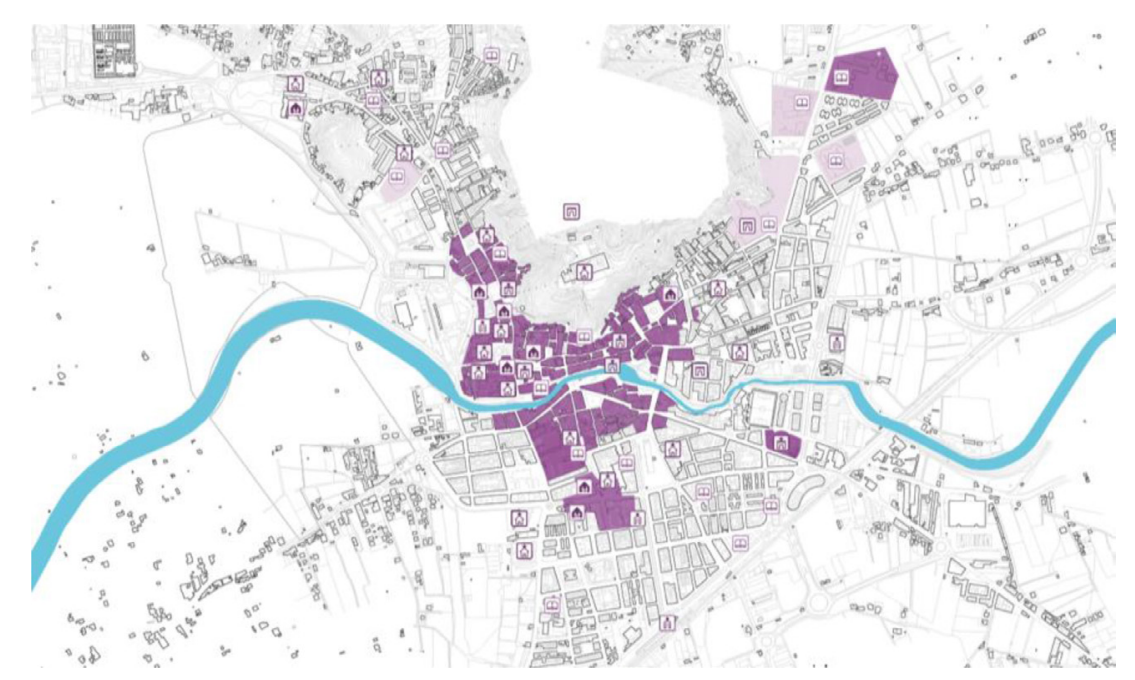

Figure 2: Historical city centre of Orihuela. 


\section{THE CITY OF ORIHUELA}

Orihuela is one of the most extensive and complex municipal districts on the Spanish Mediterranean coast. It was founded in the Visigoth era. During the Arab period, the city expanded around the roads leading to Crevillente, Callosa and Murcia. The rich land of the Rio Segura flood plain made Orihuela the most important city in the Ancient Kingdom of Valencia and as a result, it became a bishopric. This fact attracted a big number of religious orders that were mainly responsible for constructing the town's significant architectural heritage.

The municipality has 23 small settlements and two big urban conglomerations. The most important one, the city of Orihuela itself, with 35,000 inhabitants, and located in the interior, between the river Segura and the mount of San Miguel.

As it can be seen in Fig. 3, the short distance between the river and the mountain offered a very dense city with a lack of open spaces and, as many other cities in the Mediterranean area, a river without any use. An extremely rich historical centre, with several churches, abbeys and palaces faces an almost abandoned ring around the mountain and a river underused. To the river, back part of housing belonging to the main streets open their façades. Around the mountain, houses from middle class and workers were established in the past but as the city expanded, this people, completely integrated in the city life, moved to other areas leaving these houses to low class and misfit people becoming at the end a focus of conflicts.

\section{RGBG STRATEGIC MODEL}

The RGBG methodology of urban analysis was developed as a teaching tool by TU Delft professors Peter de Bois and Karen Buurmans-Niemi [8] over the course of several academic periods, and applied as part of the intensive programme Exploring the Public City [9].

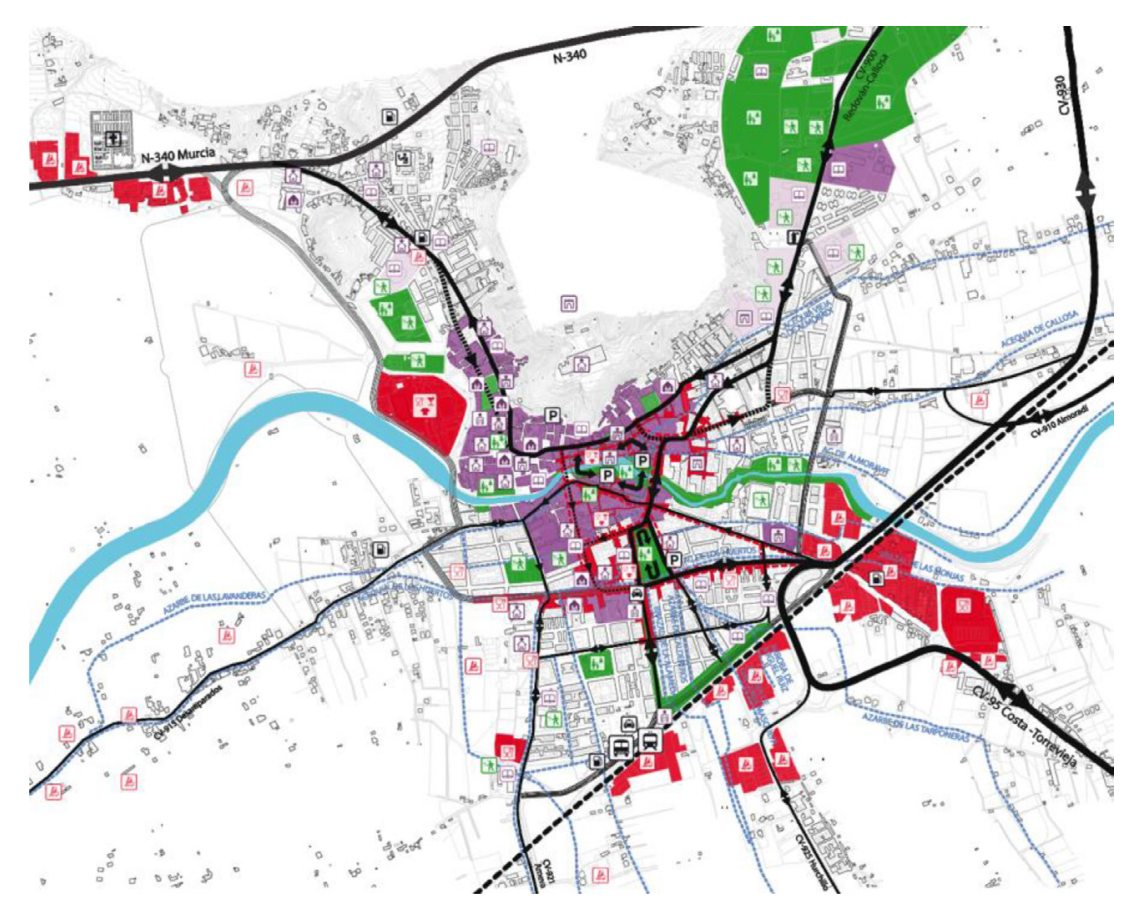

Figure 3: RGBG analysis. City centre. 


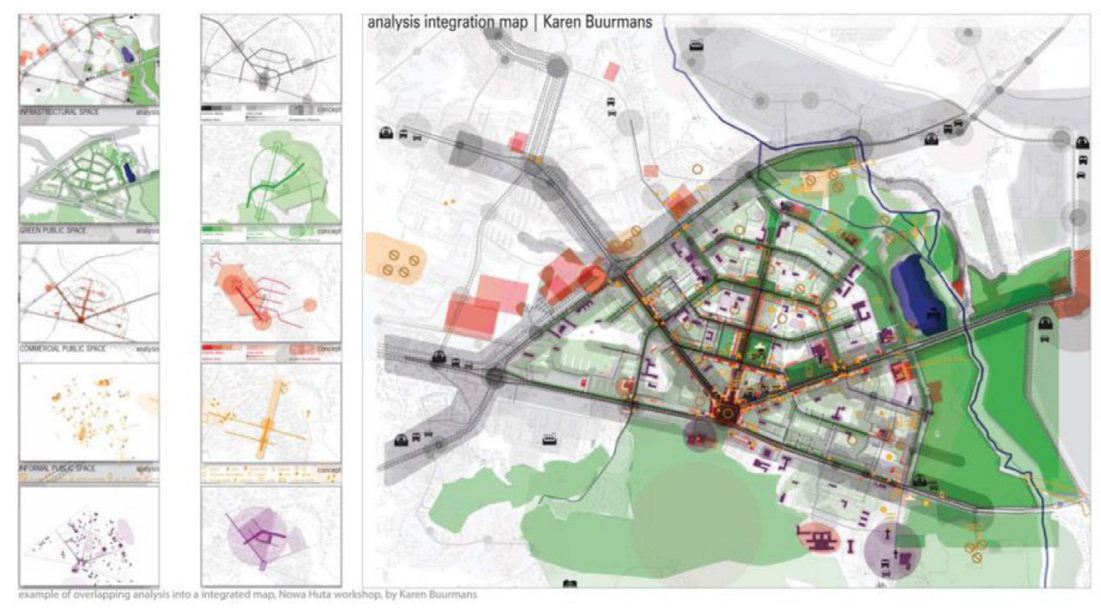

Figure 4: RGBG analysis. Nowa Huta [10].

The Strategic RGBG model is a dynamic urban analysis and design instrument, based on objective and subjective topological knowledge of the urban space. Its work structure is based on a system of overlapping layers (RGBG is an acronym for Red, Green, Blue and Grey) that highlight the pattern of spaces, functions, destinations and urban landmarks, and indicates the existence or absence of circuits that join them in a hierarchical framework.

Assessing the obtained information grouped in the different fields of work (colours) and their overlapping, it is possible to detect urban conflicts and evaluate the reasons why they have arisen. Modification of any of the layers, resolving a specific problem of a field of work, makes it possible to assess the impact on the rest of the layers, and therefore future strategies can be defined. The interaction between physical parameters, the structure of the city, permits an assessment of subjective parameters, such as levels of use and how inhabitants perceive their immediate urban surroundings as it can be seen at Fig. 4.

\section{PUBLIC COLLABORATION IN THE PROCESS OF IMPROVING PUBLIC SPACE}

In recent years, Orihuela Town Council has carried out numerous actions in order to develop a new master plan. This master plan has to substitute the current one that dates from 1990. This plan has got obsolete as during the construction bubble most of the urban land was occupied and most of the possible developments carried out. The intention of developing new strategies, but this time looking inwards the city, instead of new developments, is a reaction to the uncontrolled growth happened during the bubble and it has its origin in the need of reinforcing the city centre and recovering the conflictive areas around it.

Within the public participation program of the new master plan, the University of Alicante was hired to carry out a collaborative activity were the most important city stakeholders were invited to analyse the current city and offer their knowledge to solve the problems and design all together the future of the city. In order to coordinate all the information obtained, it was chosen the urban methodology RGBG Strategic Model and four areas of work were designed: Infrastructures and Mobility (Grey), Commercial and Industrial Fabric (Red), Historic architecture, facilities, leisure and tourism (Blue) and territorial green areas, countryside and water infrastructure (Green). 


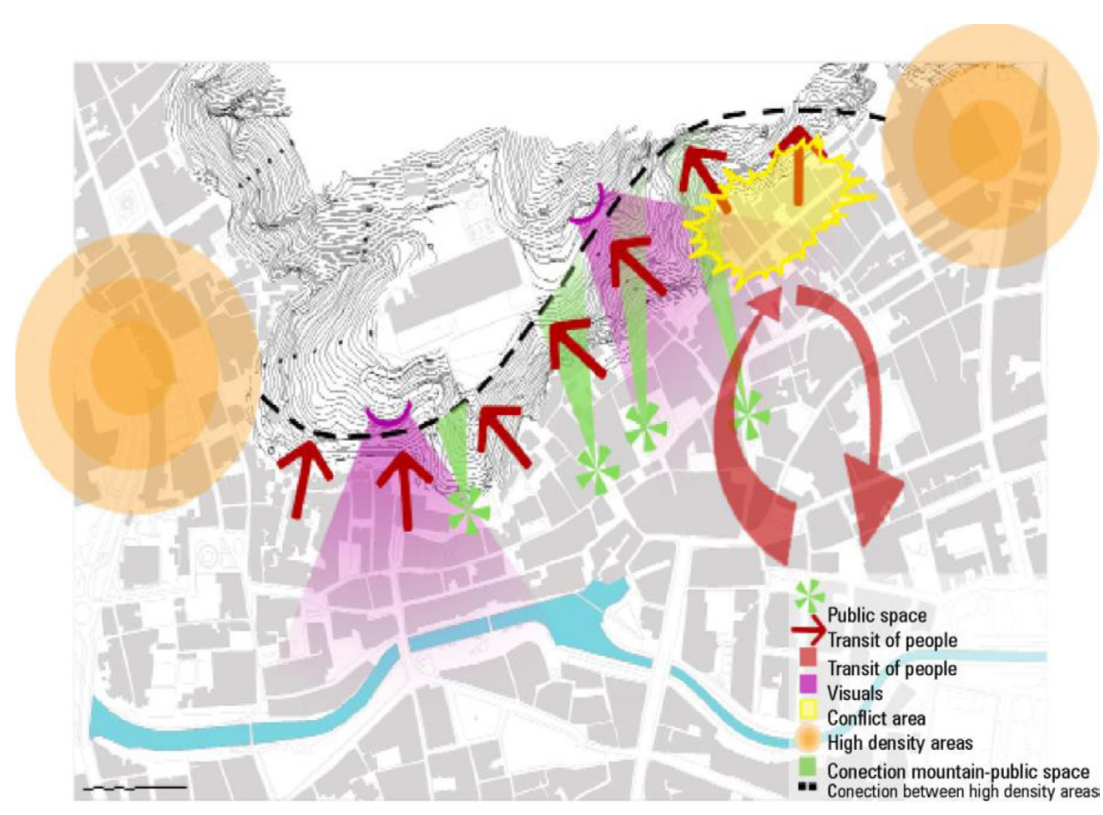

Figure 5: Analysis of the mountain's slope [11].

The application of the methodology provided very valuable information for the municipality at different levels, but it was very important the information that helped to understand the conflicts that exist in the areas around the mountain. Information about connectivity, identity and liveliness of the area was provided and conclusions about why the area was so depressed were obtained. At the same time, this subjective information was cross referenced with physical parameters as it can be seen at Fig. 5.

\section{CASE STUDIES: BARRANCO STREET AND MIGUEL HERNÁNDEZ STREET}

The ring around the mountain can be considered the main junk space at Orihuela urban frame. It is an area that it is defined by its difficult connectivity. The streets are with a unique way and without and exit at their end. Pedestrians seldom times visit the area unless they live there. Originally occupied by worker class people, the development of new areas in the city occasioned a movement to the city outskirts and many empty homes could be found in the area. The lack of maintenance and the very cheap prices attracted other type of people, most of times misfit, so the areas became a focus of conflicts with a very high rate of unemployment.

The area of Barranco Street is one of the most complex areas of the city from the geographical point of view. It is located in the east part of the city and its name means 'ravine'. Therefore, an important part of the mountain rain water goes through it in the way to the river Segura. Traditionally, special interventions have been carried out in this area in order to mitigate the danger especially during autumn floods. The area is composed by three parallel streets perpendicular to the mountain with no connexions in the upper part. In recent time, the municipality demolished some ruined buildings leaving the rubble there. 


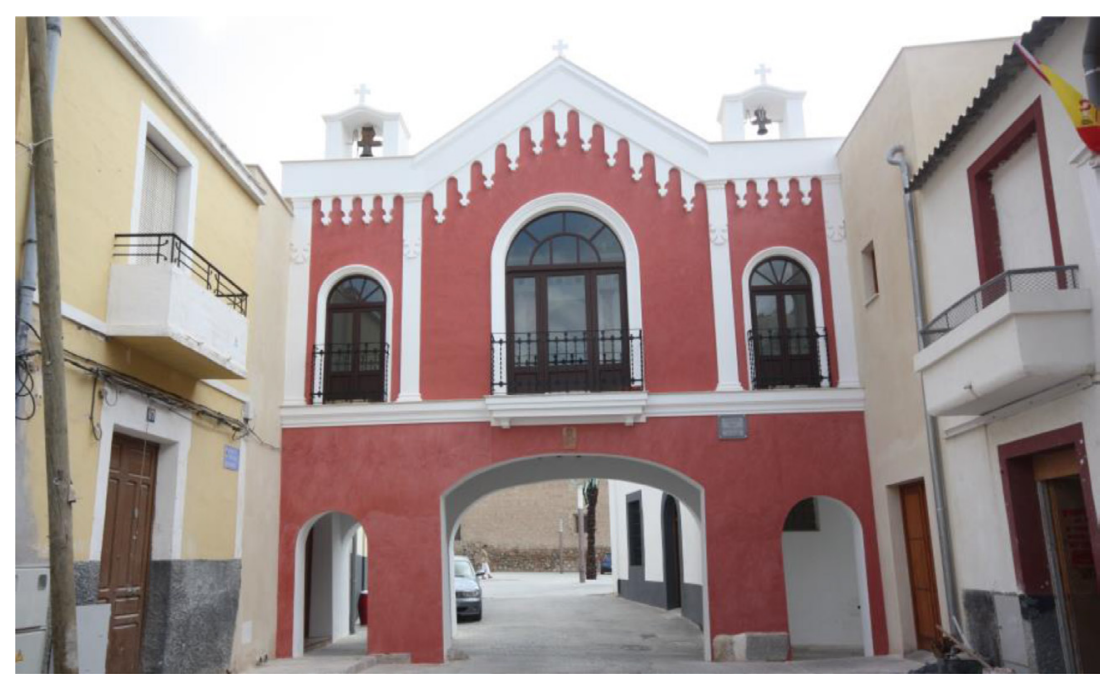

Figure 6: Chapel of our lady of Monserrate.

The area around Miguel Hernández Street suffers similar problems. Originally developed as an urban development at the end of the XVIII century it is one of the most picturesque parts of the city. It is parallel to one of the former roads that exit the city. At the end of the street, in the former city border, a chapel addressed to Our Lady of Monserrate (Fig. 6) was located defining the limit and giving sense to the urban development. Behind the Chapel some touristic milestones can be found, the house were the poet Miguel Hernandez was born and the College of Santo Domingo among others. This equipments should have transformed this area in a wealthy active part of the city, but this situation is far to occur. The difficulties of introducing this area in the daily circuits have transformed it in one of the most conflictive areas of the city.

As it happens in the Barranco Street, the area is composed by perpendicular streets towards the mountain with big mobility problems.

\section{RGBG ANALYSIS OF THE AREAS}

The development of the activities included in the revision of the city Master Plan and the application of the RGBG Strategic Model showed the same conflicts in both areas. From the connectivity point of view, there is a lack of a balanced urban frame. In both cases, there is a main axe that goes out from the city (Figs 7 and 8) but the shape of the city and the slope of the mountain conditions pedestrian mobility.

In the case of Barranco Street, there are some monuments in the surroundings. In the case of Miguel Hernández Street, there are monuments and equipments. In both cases, the shape of the city and the lack of poles of attraction in the slope of the mountain makes people avoid this area. This situation is reinforced when the urban milestones, placed in a short distance, are monuments that are open during short periods of time.

In both cases, the areas are related to a big open space but as the Mount San Miguel has never been considered as part of the city there is not a feeling of identification in the inhabitants of the area. 


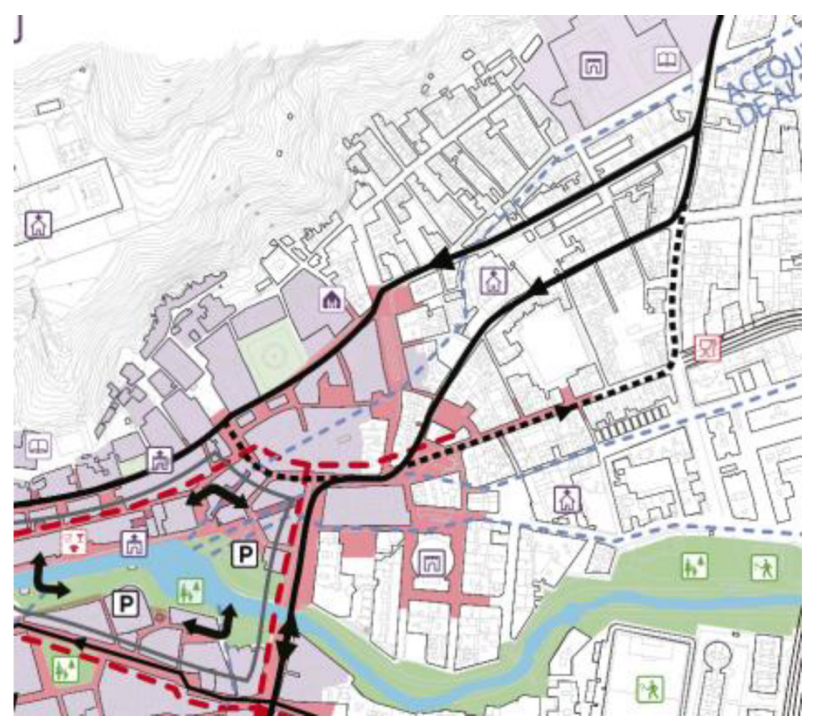

Figure 7: RGBG Analysis - Miguel Hernández Street.

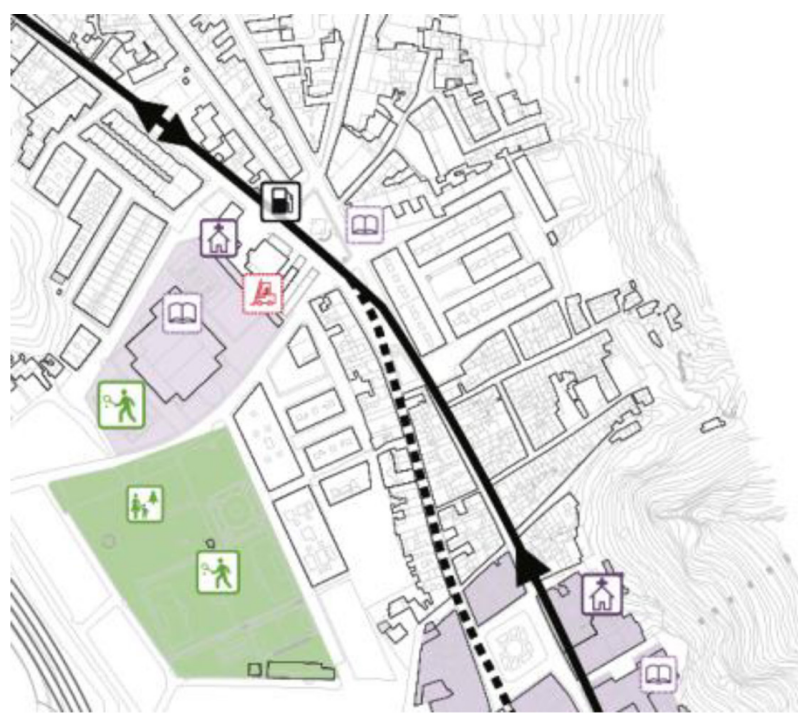

Figure 8: RGBG Analysis - Barranco Street.

The lack of activities and uses in both areas can be stated at the commercial and equipments plans. The neighbourhood shops are far from these streets, close to the main connectivity axes. Else than housing, no other type of buildings are located in the area.

The overlap of all the obtained information confirms both areas as candidate for becoming urban junk spaces, an isolated part of the city with a lack of uses and activities that could enrich city life. 


\section{PROPOSAL AND PEOPLE INVOLVEMENT}

The analysis of the obtained information during the RGBG process showed that the origin of the conflicts could be related to the lack of activities in the area, the difficulties in mobility and the difficult relation with the mountain.

The proposal carried out by the municipality was based in the improvement of the quality of public space by increasing people presence in the streets. Therefore, after removing all the debris, it was projected a path that could connect the different parts of the city centre around the mountain's slope. With this solution, the problem of connectivity wanted to be solved and offered the possibility of visiting the city from the heights.

The still existing problem of people identification with their neighbourhood was tried to be solved through an employment workshop. The way to involve people in the process of the urban regeneration was making the neighbours part of the process. By this way, instead of hiring professionals for doing the construction, neighbours were hired and taught a new job to compensate the lack of employment in both areas.

\section{NEIGHBOUR'S ATTITUDE}

The development of the intervention faced two attitudes within the neighbours. There was a group that rapidly supported it and a group that rejected it. The group of people that still had a relation with the former inhabitants of the area, integrated in the society of Orihuela were rapidly interested in the actuation and the refurbishment of the neighbourhood. They joined the initiative and applied to participate as workers. These people are mainly located in the lower part of the perpendicular streets closest to the main focus of activity and uses as it is shown at figures 9 and 10.

In the other hand, we can find the groups of people that directly rejected the intervention and were annoyed with the presence of people working on the streets. This group of people were located in the upper part of both areas close to the mountain, far from the main uses and focus of activities. In most of the cases, they were illegally occupying the houses and in some cases their job were related to illegal activities.

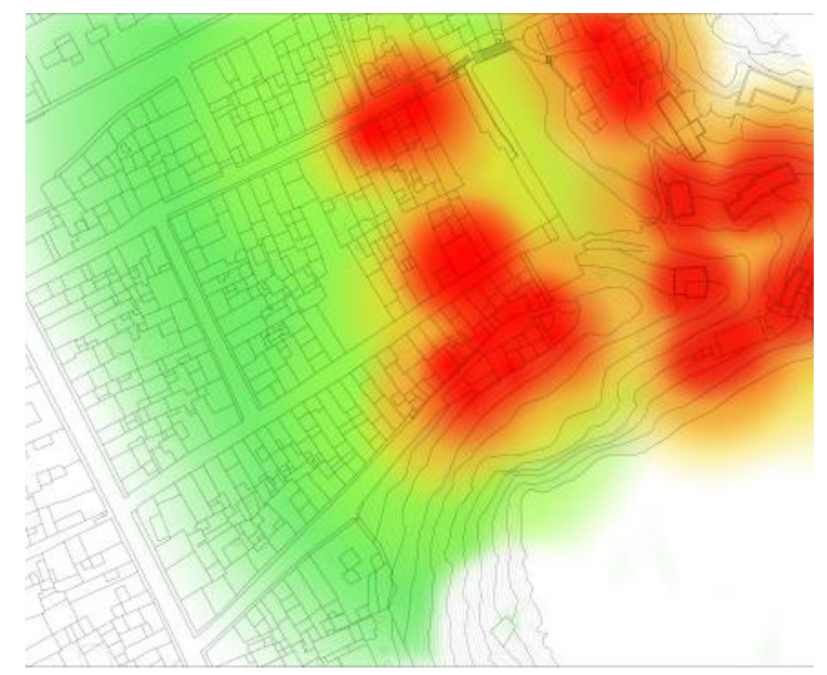

Figure 9: Conflictive families - Miguel Hernández Street. 


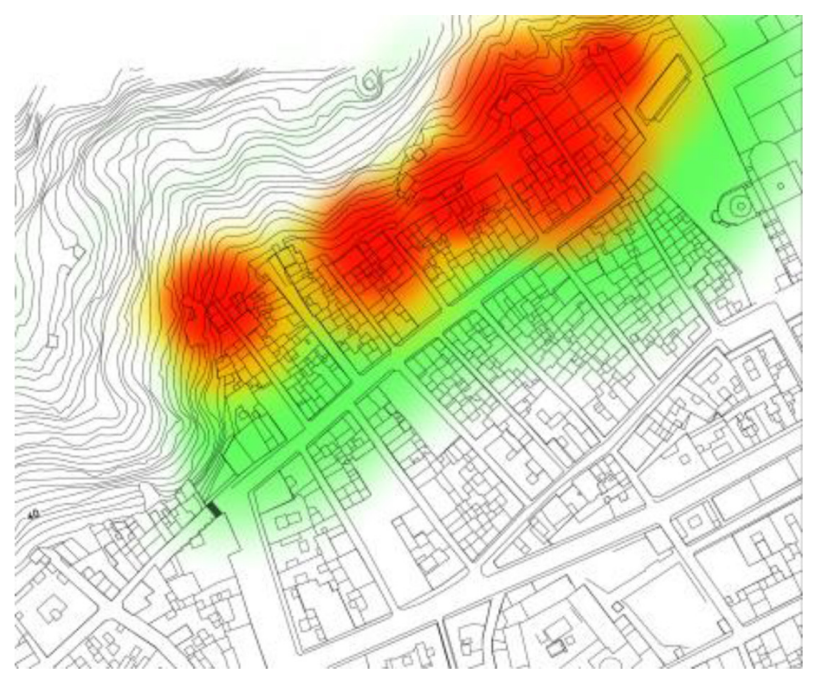

Figure 10: Conflictive families - Barranco Street

\section{MAINTENANCE}

After the end of the restoration tasks, a difference in the conservation of the public space can be identified with the above mentioned neighbour's groups. The groups that participated in the restoration has started doing a proper use of public space extending their homes and keeping it perfectly in use. An improvement in the level of activity has occurred and the streets still keep the image that was obtained at the end of the employment workshops. In the other hand, the areas occupied by non-integrated people started developing a wrong use of public space damaging the urban furniture set during the construction. Nevertheless, the situation is better than before the urban restoration as the path developed around the mountain skirts is attracting tourists and their presence is restricting the wrong use of public space.

\section{CONCLUSIONS}

The development of public initiatives is confirmed as a good tool for recovering damaged public spaces. The feeling of belonging is crucial in order to valuate the urban environment and in order to give it a proper use. Involving inhabitants in the process of recovering public space is shown as very useful tools as at the end inhabitants keep on using it as they feel it as part of their homes.

The RGBG Strategic Model is confirmed as a valid alternative as an urban analysis methodology, which examines the physical environment with subjective parameters such as levels of activity in the urban public space. The sequential compilation of data, ordered in layers and subsequent overlapping permits an analysis of the situation of the urban space by sector and detection of existing conflicts.

The information provided by the RGBG Strategic Model confirmed the need of the creation of a structure connecting the city in the mountain's slope so that the presence of visitors could increase the level of activity and attract improvements to the area. This improvement related to increasing people identify over their neighbourhoods can help improving quality of public space. 


\section{ACKNOWLEDGEMENTS}

The Orihuela 2,030 Forum is an initiative promoted by Orihuela Town Council which commissioned the University of Alicante to apply its RGBG tool to the process of revising the Master Plan. Compilation for the information for each of the fields of work was possible thanks to the endeavours of the institutions, agents and professionals in the town of Orihuela who took part in this activity.

\section{REFERENCES}

[1] Lynch, K., The Image of the City, MIT Press: Cambridge Massachussets, 1960.

[2] Reijndorp, A. \& Maarten, H., In Search of New Public Domain. Analysis and Strategy, NAI publishers: Rotterdam, 2001.

[3] De Bois, P. \& Buurmans, K., To know the path is to rule the system. Case study New Town Almere (NL), Delft University of Technology: Deflt, 2007.

[4] Buurmans, K., To know the path is to rule the system. Frame - Âttern - Circuit analysis (FPC). At Proccedings 10th Anniversay Conference European Urban Research Association (EURA), The Vital City, Glasgow, 2007.

[5] De Bois, P. \& Buurmans, K., To know the path is to rule the system. Case study New Town Almere (NL), Delft University of Technology: Deflt, p. 3, 2007.

[6] Gehl, J., Life Between Buildings: Using Public Space, Danish Architectural Press: Copenhagen, 1971.

[7] Koolhas, R., Junkspace. October, 100, pp. 175-190, 2002.

[8] De Bois, P. \& Buurmans, K., RGBG Strategic Model, a Scenario Analysis \& Design Method, Delft University of Technology: Delft, 2006.

[9] Galiano, A., Koehler, M., De Bonth, L. \& Ivorra, G., Exploring the Public City. Strategic Public Spaces for Sustainable New Town Development, Publicaciones Universidad de Alicante: Alicante, 2009.

[10] Buurmans, K., De Bois, P. \& Wicher, W., Exploring the Public City. Transforming the Post-War City, Nowa Huta, Cracow University of Technology; Cracow, 2007.

[11] Galiano, A. \& Echarri, V. (eds), Foro 2030: Desarrollo, Aplicación y Mejora de la Metodología de Trabajo EPC en la Ciudad de Orihuela, Universidad de Alicante: Alicante, 2014. 